\title{
REVISTA DE INVESTIGACIÓN CLÍNICA -CLINICAL AND TRANSLATIONAL INVESTIGATION-: EDITORS' CHOICES 6 YEARS LATER
}

\author{
Alfredo Ulloa-Aguirre ${ }^{1 *}$, Luis Oñate-Ocaña ${ }^{2}$, and Moisés Selman ${ }^{3}$ \\ 1Editor-in-Chief, Revista de Investigación Clínica -Clinical and Translational Investigation- (RIC) and Red de Apoyo \\ a la Investigación (RAI), Universidad Nacional Autónoma de México and Instituto Nacional de Ciencias Médicas \\ y Nutrición Salvador Zubirán (INCMNSZ), Mexico City; ${ }^{2}$ Deputy Editor, RIC, and Instituto Nacional de Cancerología \\ (INCan), Mexico City; ${ }^{3}$ Deputy Editor, RIC, and Instituto Nacional de Enfermedades Respiratorias "Ismael Cosío \\ Villegas" (INER), Mexico City, Mexico
}

\begin{abstract}
In this article, a series of original manuscripts and reviews published between 2015 and 2021 in the Revista de Investigación Clínica -Clinical and Translational Investigation- chosen by the Editors are presented. The articles were selected according to what the editors considered are the most outstanding contributions based on originality, and the potential impact of the information provided on translational medicine, rather than on the number of readings and citations. (REV INVEST CLIN. 2021;73(5):288-96)
\end{abstract}

Key words: Revista de Investigación Clínica. Clinical and Translational Investigation. Abstracts.

As described in the previous article on the history of the Revista de Investigación Clínica $(R I C)^{1}$, the fourth and current era of the journal began with the first 2015 issue. The new editorial policies of the editors gave preference to original articles of both national and international interest, mainly to contributions from clinical and biomedical studies. In addition to original articles, other types of articles also have been published, including reviews written by experts in different fields, perspectives in which experienced authors propose current and novel venues for diagnosis and treatment of human diseases, thematic series on a given subject, and reviews on a particular topic published in a single issue (Thematic issues). Table 1 shows the most read articles during 2020 published in the RIC -Clinical and Translational Investigation-, and those from September 2016 to December 2020 are shown in table 2.

For the present article, the Editors chose what we consider the most outstanding contributions based on originality, and the potential impact of the information provided on translational medicine. It is important to emphasize that our choices do not
*Corresponding author:

Alfredo Ulloa-Aguirre

E-mail: aulloaa@unam.mx
Received for publication: 28-05-2021

Approved for publication: 03-06-2021

DOI: $10.24875 / R I C .21000286$

0034-8376 / (c) 2021 Revista de Investigación Clínica. Published by Permanyer. This is an open access article under the CC BY-NC-ND license (http://creativecommons.org/licenses/by-nc-nd/4.0/). 
Table 1. RIC -Clinical and Translational Investigation-: The most read articles of 2020

\begin{tabular}{|c|c|c|}
\hline Title of the article & Reference & Number of readings \\
\hline $\begin{array}{l}\text { Respiratory Impact of Electronic Cigarettes and } \\
\text { "Low-Risk" Tobacco. } \\
\text { Thirión-Romero I, et al. }\end{array}$ & $\begin{array}{l}\text { Rev Invest Clin 2019;71(1):17-27. } \\
\text { doi: } 10.24875 / R I C .18002616\end{array}$ & 1,852 \\
\hline $\begin{array}{l}\text { Clinical and Epidemiological Characteristics of Patients } \\
\text { Diagnosed with COVID-19 in a Tertiary Care Center } \\
\text { in Mexico City: A Prospective Cohort Study. } \\
\text { Ortiz-Brizuela E, et al. }\end{array}$ & $\begin{array}{l}\text { Rev Invest Clin 2020;72(3):165-177. } \\
\text { doi: 10.24875/RIC.20000211 }\end{array}$ & 1,464 \\
\hline $\begin{array}{l}\text { Nutritional Assessment Tools for the Identification } \\
\text { of Malnutrition and Nutritional Risk Associated } \\
\text { with Cancer Treatment. } \\
\text { Castillo-Martínez L, et al. }\end{array}$ & $\begin{array}{l}\text { Rev Invest Clin } 2018 ; 70(3): 121-125 \text {. } \\
\text { 2018;70(3):121-125. } \\
\text { doi: } 10.24875 / \text { RIC. } 18002524\end{array}$ & 1,317 \\
\hline $\begin{array}{l}\text { Universal Masking during COVID-19 Pandemic - } \\
\text { Current Evidence and Controversies. } \\
\text { Quintana-Díaz MA and Aguilar-Salinas C. }\end{array}$ & $\begin{array}{l}\text { Rev Invest Clin 2020;72(3):144-150. } \\
\text { doi: } 10.24875 / R I C .20000196\end{array}$ & 1,302 \\
\hline $\begin{array}{l}\text { Biology of Healthy Aging and Longevity. } \\
\text { Carmona JJ and Michan S. }\end{array}$ & Rev Invest Clin 2016;68(1):7-16. & 1,116 \\
\hline $\begin{array}{l}\text { Familial Combined Hyperlipidemia: Current Knowledge, } \\
\text { Perspectives, and Controversies. } \\
\text { Bello-Chavolla OY, et al. }\end{array}$ & $\begin{array}{l}\text { Rev Invest Clin 2018;70(5):224-236. } \\
\text { doi: } 10.24875 / R I C .18002575\end{array}$ & 1,048 \\
\hline $\begin{array}{l}\text { The Role of Immunosenescence in the Development } \\
\text { of Age-Related Diseases. } \\
\text { Fülöp T, et al. }\end{array}$ & Rev Invest Clin 2016;68(2):84-91. & 969 \\
\hline $\begin{array}{l}\text { Impact of Comorbidities in Mexican SARS-CoV-2-Positive } \\
\text { Patients: A Retrospective Analysis in a National Cohort. } \\
\text { Kammar-García A, et al. }\end{array}$ & $\begin{array}{l}\text { Rev Invest Clin 2020;72(3):151-158. } \\
\text { doi: } 10.24875 / R I C .20000207\end{array}$ & 967 \\
\hline $\begin{array}{l}\text { Smoking Cessation Treatments: Current Psychological } \\
\text { and Pharmacological Options. } \\
\text { García-Gómez L, et al. }\end{array}$ & $\begin{array}{l}\text { Rev Invest Clin 2019;71(1):7-16. } \\
\text { doi: } 10.24875 / R I C .18002629\end{array}$ & 944 \\
\hline $\begin{array}{l}\text { Infusion of Convalescent Plasma is Associated with } \\
\text { Clinical Improvement in Critically III Patients } \\
\text { with COVID-19: A Pilot Study. } \\
\text { Olivares-Gazca JC, et al. }\end{array}$ & $\begin{array}{l}\text { Rev Invest Clin 2020;72(3):159-164. } \\
\text { doi: } 10.24875 / \text { RIC.20000237 }\end{array}$ & 910 \\
\hline
\end{tabular}

necessarily correspond to the most cited or read papers (Tables 1 and 2 ), as citation rates may not actually reflect the essence of novelty publication because they usually depend on the particular field (i.e., specialty) of the publication. In fact, it is expected that "hot" topics such as those corresponding to highly prevalent diseases (e.g., type 2 diabetes, obesity and hyperlipidemia, all associated with increased cardiovascular risk) or diseases with high mortality (some cancers such as pancreatic and lung cancers), will be more read and cited. Needless to say about papers on Coronavirus disease (Covid-19)! In addition, many articles may be considerably cited because of self-citations and, frequently, nonreplicable publications are cited more than those replicable ${ }^{2}$. On the other hand, it is well-known that good reviews are always highly cited, and in fact, they have served to many journals (including ours) to increase their readability and impact factor (IF), currently a debatable metric due to its common misuse almost all over the world to evaluate scientific work. At least for the purposes of our journal, the translational potential on diagnosis and treatment of medical conditions (rare or frequent) of a given paper or review is what was taken into account for our choices. Although this was a difficult task because it meant to choose 2-3 papers/year from over 241 original articles (including Research Letters and Brief Communications) and reviews, it was, as Editors of the journal, our privilege. We apologize in advance for not including other relevant papers due to the 
Table 2. RIC -Clinical and Translational Investigation-: The most read articles from September 2016 to December 2020

\begin{tabular}{|c|c|c|}
\hline Article title & Reference & Readings \\
\hline $\begin{array}{l}\text { Biology of Healthy Aging and Longevity. } \\
\text { Carmona JJ, and Michan S. }\end{array}$ & Rev Invest Clin 2016;68(1):7-16. & 3,995 \\
\hline $\begin{array}{l}\text { Respiratory Impact of Electronic Cigarettes and } \\
\text { "Low-Risk" Tobacco. } \\
\text { Thirión-Romero I, et al. }\end{array}$ & $\begin{array}{l}\text { Rev Invest Clin 2019;71(1):17-27. } \\
\text { doi: } 10.24875 / R I C .18002616\end{array}$ & 3,926 \\
\hline $\begin{array}{l}\text { The Role of Immunosenescence in the Development } \\
\text { of Age-Related Diseases. } \\
\text { Fülöp T, et al. }\end{array}$ & Rev Invest Clin 2016;68(2):84-91. & 2,811 \\
\hline $\begin{array}{l}\text { Frailty and Sarcopenia: The New Geriatric Giants. } \\
\text { Morely JE. }\end{array}$ & Rev Invest Clin 2016;68(2):59-67 & 2,701 \\
\hline $\begin{array}{l}\text { Nutritional Assessment Tools for the Identification } \\
\text { of Malnutrition and Nutritional Risk Associated } \\
\text { with Cancer Treatment. } \\
\text { Castillo-Martínez L, et al. }\end{array}$ & $\begin{array}{l}\text { Rev Invest Clin } 2018 ; 70(3): 121-125 \\
\text { 2018;70(3):121-125. } \\
\text { doi: } 10.24875 / \text { RIC.18002524 }\end{array}$ & 2,654 \\
\hline $\begin{array}{l}\text { Familial Combined Hyperlipidemia: Current Knowledge, } \\
\text { Perspectives, and Controversies. } \\
\text { Bello-Chavolla OY, et al. }\end{array}$ & $\begin{array}{l}\text { Rev Invest Clin 2018;70(5):224-236. } \\
\text { doi: } 10.24875 / R I C .18002575\end{array}$ & 2,491 \\
\hline $\begin{array}{l}\text { Use of Functional Foods and Oral Supplements as } \\
\text { Adjuvants in Cancer Treatment. } \\
\text { Serna-Thomé G, et al. }\end{array}$ & $\begin{array}{l}\text { Rev Invest Clin 2018;70(3):136-146. } \\
\text { doi: } 10.24875 / R I C .18002527\end{array}$ & 1,851 \\
\hline $\begin{array}{l}\text { Smoking Cessation Treatments: Current Psychological } \\
\text { and Pharmacological Options. } \\
\text { García-Gómez L, et al. }\end{array}$ & $\begin{array}{l}\text { Rev Invest Clin 2019;71(1):7-16. } \\
\text { doi: } 10.24875 / R I C .18002629\end{array}$ & 1,770 \\
\hline $\begin{array}{l}\text { Practical Approach to the Evaluation and Management } \\
\text { of Rheumatoid Arthritis-Interstitial Lung Disease } \\
\text { based on its Proven and Hypothetical Mechanisms. } \\
\text { Paulin F, et al. }\end{array}$ & $\begin{array}{l}\text { Rev Invest Clin2017;69(5):235-242. } \\
\text { doi: } 10.24875 / \text { ric. } 17002162\end{array}$ & 1,731 \\
\hline $\begin{array}{l}\text { Clinical and Epidemiological Characteristics of Patients } \\
\text { Diagnosed with COVID-19 in a Tertiary Care Center } \\
\text { in Mexico City: A Prospective Cohort Study. } \\
\text { Ortiz-Brizuela E, et al. }\end{array}$ & $\begin{array}{l}\text { Rev Invest Clin 2020;72(3):165-177. } \\
\text { doi: } 10.24875 / R I C .20000211\end{array}$ & 1,464 \\
\hline
\end{tabular}

space constraints imposed by this particular thematic issue of the journal. So here are the Editors' choices picked from the last 6 years of the RIC -Clinical and Translational Investigation-.

\section{SELECTED ORIGINAL PAPERS}

\section{Hepatitis C screening in the general population}

Clara Corona-Lau, Linda Muñoz, Enrique Wolpert, Luz Ma. Aguilar, Margarita Dehesa, Concepción Gutiérrez, David Kershenobich. Rev Invest Clin 2015;67:104-108.
Given that Hepatitis $C$ is a silent disease, patients infected with the hepatitis $C$ virus are usually poorly aware for many years of having the disease. In this study, Corona-Lau et al. ${ }^{3}$ reported the results from the screening of 32,945 volunteers ( $75 \%$ belonging to the group of 21-50 years of age) during the period of 2000-2014, employing a chemiluminescence enzyme immunoassay. Anti-hepatitis $C$ virus was positive in $0.58 \%$ of the subjects ( 194 patients), of which 129 were confirmed by polymerase chain reaction (PCR), yielding an overall prevalence of $0.39 \%$ in the sample analyzed. Although the data need to be updated to search for trends in the prevalence of positive cases, the study is of great value considering the number of individuals tested as well as the 
laboratory procedures employed in the analysis. Determining the prevalence of hepatitis $\mathrm{C}$ viremia in the general population is important since this infection may lead to chronic liver disease. The authors conclude that their findings are of relevance when deciding the allocation of resources in the era of new pharmacological approaches to treat this disease, starting treatment earlier to prevent advanced liver disease.

\section{Distinguishing intracerebral hemorrhage from acute cerebral infarction through metabolomics}

Xuxin Zhang, Yanzhao Li, Yan Liang, Pitong Sun, Xue Wu, Jinhui Song, Xiaoyu Sun, Mo Hong, Peng Gao, Dongfeng Deng. Rev Invest Clin 2017;69:319-328.

Stroke is the major leading cause of death in adults worldwide. Essentially, stroke can be ischemic or hemorrhagic. Typically, diagnosis is made by neuroimaging ${ }^{4}$. Both conditions share common clinical manifestations in the acute, bedside setting, but require opposite therapeutic strategies. In this study, Zhang et al. ${ }^{5}$ enrolled 129 patients with ischemic stroke and 128 with hemorrhagic stroke diagnosed by computed tomography and/or magnetic resonance imaging, and 65 healthy controls. The authors compared changes in metabolites between both conditions and controls, using dried blood spot-based direct infusion mass spectrometry technology, and found 11 clinically relevant biomarkers based on multivariate analysis. An artificial neural network model was constructed based on these biomarkers and the authors describe an external validation of this model, stating a diagnostic sensitivity of 0.84 (95\% Confidence Interval $[\mathrm{Cl}]$ 0.74-0.94) and specificity of 0.77 (95\% $\mathrm{Cl} 0.65-0.88)$. This study is relevant because it suggests that, besides high-technology imaging, metabolomic analysis is a promising tool for fast differentiation between ischemic or hemorrhagic stroke. However, the results from this study should be taken with caution since the search for these metabolites was empirical, without a clear pathophysiological basis. Furthermore, it should be considered that the levels of the metabolites investigated may vary depending on gender, age, prevalence of diabetes, obesity or hypertension, and drugs administered or timing of their administration 6 .

\section{The role of stents as bridge to surgery for acute left-sided obstructive colorectal cancer: Meta-analysis of randomized controlled trials}

\author{
Ping Yang, Xiu-Feng Lin, Kai Lin, Wei Li. Rev Invest Clin
} 2018;70:269-278.

Colorectal cancer is a major health problem worldwide. Left-sided neoplasms are frequently diagnosed as colonic occlusion and, in selected cases, the role of self-expanding metallic stents to permit resolution of the occlusion and to prepare the patient to definitive surgery is a matter of controversy ${ }^{7}$. In this meta-analysis ${ }^{8}$, the authors included eight randomized trials comprising patients who received a colonic stent or directly underwent surgery; 497 individuals were studied. Patients who underwent resolution by stent received a colonic stoma less frequently and a primary anastomosis more frequently than those who went directly to surgery. The frequency of surgical complications was lower in the group who underwent colonic stents as well. However, the frequency of cancer recurrence was higher in this latter group. Considering the heterogeneity of surgical randomized clinical trials, the absence of blinding, and different inclusion criteria, the authors concluded that the resolution of colonic occlusion by the use of stents increases the frequency of primary anastomosis as well as the risk of cancer recurrence. Probably, the pre-operative use of metal stents to decompress colonic occlusion must be considered with caution, selecting patients with clear risk factors for surgical morbidity and increased probability of having a definitive stoma, and selecting the best preoperative chemotherapy for each case ${ }^{9}$.

\section{The effect of single-dose intraperitoneal bevacizumab on peritoneal adhesion formation}

Gokce Acun, Hakan Ozdemir, Oguzhan Sunamak, Zehra Unal Ozdemir, Emel Baskan, Mete Yazi, Berna Zavas, Ugur Berberoglu. Rev Invest Clin 2018;70:279-284.

Intestinal occlusion caused by surgical adhesions is a leading cause of abdominal surgical emergencies, and a major cause of morbidity, mortality, and costs 
at the emergency room ${ }^{10}$. Therefore, various treatments that aim to reduce the formation of surgical adhesions are being investigated, and it is a quite controversial matter. Angiogenesis and adhesion can be blocked by inhibiting vascular endothelial growth factor (VEGF). In this study by Acun et al. ${ }^{11}$ an experimental model in rats is presented, employing bevacizumab to reduce adhesion formation in a cecum abrasion model, pretending to demonstrate the effect of VEGF blockade. The authors randomly assigned 32 Wistar rats into two groups, the first was treated with intraperitoneal bevacizumab and the second with placebo. Two weeks after surgery, adhesion formation was evaluated and found to be lower in the treated group. The authors concluded that bevacizumab was effective in preventing the development of intraperitoneal adhesion in rats. However, its role in the prophylaxis of adhesion formation could be limited by costs and adverse effects, factors that should be anticipated in clinical trials in humans. This study is an Editors' choice because of its seminal approach to a major surgical problem that can stimulate further clinical research on this important issue ${ }^{12}$.

\section{Factors influencing achievement of low-density lipoprotein cholesterol (LDL-C) goals in mexico: The International Cholesterol Management Study}

Omar Y. Bello-Chavolla, Carlos A. Aguilar-Salinas. Rev Invest Clin. 2019;71:408-416.

High LDL-C level, a strong risk factor for cardiovascular disease ${ }^{13}$, is among the most common forms of dyslipidemia in Mexicans, although remains usually underdiagnosed and untreated. In this cross-sectional observational study ${ }^{14}$ that included 623 patients receiving stable lipid-lowering therapy (statins), the authors evaluated the achievement of LDL-C goals in Mexico in the real life. The results showed that only around $25 \%$ of the patients with very-high or high cardiovascular risk, and half of the patients with moderate risk achieved their LDL-C level goals. A number of factors associated to the lack of accomplishment were identified, including statin intolerance, obesity, metabolic syndrome, type 2 diabetes, female gender, and use of public health-care service. These findings indicate that achievement of LDL-C goals is suboptimal in Mexico, unveiling several gaps in the application of this therapy, and suggesting that their implementation should be adapted to the patient's needs and profile.

\section{Clinical and epidemiological characteristics of patients diagnosed with COVID-19 in a tertiary care center in mexico city: a prospective cohort study}

Edgar Ortiz-Brizuela, Marco Villanueva-Reza, María F. González-Lara MF, Karla M. Tamez-Torres, Carla M. Román-Montes, Bruno A. Díaz-Mejía, et al. Rev Invest Clin. 2020;72:252-258.

The COVID-19 pandemic triggered an unprecedented clinical challenge for scientists, clinicians, epidemiologists, and health-care systems ${ }^{15,16}$. It was soon demonstrated that the severity of symptoms varies considerably from being asymptomatic to manifest as a critical disease with lethal complications. This pioneer, multi-author study ${ }^{17}$ examined, at the beginning of the first wave of the pandemic in Mexico, the clinical features of 309 COVID-19 patients searching for differences between outpatients and hospitalized patients, both those who required intensive care unit (ICU) and those who did not. The results showed that hospitalization was more frequent in middle-age obese or overweight men and in older individuals with different comorbidities. Patients requiring intensive care, primarily due to respiratory failure demanding mechanical ventilation, presented several laboratory parameters suggestive of a more intense inflammatory response, a more severe prothrombotic state, and a higher frequency of cardiac and liver involvement. This study identified in the population attended in a third level hospital in Mexico City, several clinical, demographic, and laboratory differences between ambulatory and hospitalized COVID-19 patients, including those who needed intensive care treatment.

\section{Coronary artery calcium is associated with Ipa gene variant RS7765803-C in Mexican mestizo population. The GEA Project}

Guillermo C. Cardoso-Saldaña, Rosalinda PosadasSánchez, María del C. González-Salazar, José M. 
Fragoso-Lona, Gilberto Vargas-Alarcón. Rev Invest Clin. 2020;72:61-68.

Strong evidence supports the notion that high serum levels of lipotrotein(a) $[\mathrm{Lp}(\mathrm{a})]$ is an independent and important risk factor for atherosclerotic disease $\mathrm{e}^{18}$ and that some single-nucleotide polymorphisms (SNPs) are associated with their serum concentrations. However, the association between LPA gene variants and coronary artery calcification (CAC), an atherosclerosis marker that predicts cardiovascular events, is unclear. In this study, that included 1594 individuals, six SNPs were examined and related to $L p(a)$ levels and the presence of $\mathrm{CAC}^{19}$. Three polymorphisms were associated with high levels of $L p(a)$ with strong association with rs7765803-C. Importantly, this polymorphism conferred a 1.7-fold increase in the risk for coronary artery disease. These findings demonstrate for the $1^{\text {st }}$ time and in a well-characterized MexicanMestizo population, that the rs7765803-C allele of LPA is significantly associated with high concentrations of $L p(a)$ as well as with the presence of subclinical atherosclerosis (CAC).

\section{Analysis of the endometrial transcriptome at the time of implantation in women receiving a single post-ovulatory dose of levonorgestrel (LNG) or mifepristone}

Ana E. Barrios-Hernández AE, Marta Durand-Carbajal, Claudia C. Vega, Fernando Larrea. Rev Invest Clin 2020; 72:363-371.

Levonorgestrel (LNG) is a progesterone receptor agonist widely used as a contraceptive, including its postcoital administration as an emergency contraceptive. In this study, Barrios-Hernández et al. ${ }^{20}$ assessed the effects of LNG on implantation. To this end, they applied a microarray expression approach to study gene expression in endometrial samples taken during the luteal phase of the menstrual cycle from women treated with LNG after ovulation. Post-ovulatory administration of LNG or mifepristone (a progesterone receptor antagonist) caused changes in gene expression compared to those in the control group. Nevertheless, bioinformatics analysis of differentially expressed genes found that LNG did not significantly alter the molecular activity of the biofunctions related to decidualization and embryo implantation as seen with mifepristone. These results contribute with evidence to the concept that LNG has no effects on endometrial receptivity when administered after ovulation as an emergency contraceptive, and that its mechanism of action rather resides in inhibiting or delaying ovulation when administered before the ovulatory peak of luteinizing hormone ${ }^{21}$ without effects when administered after ovulation has occurred. This information is important for the acceptance and use of LNG as an approach for emergency contraception, particularly in some conservative communities of the society.

\section{Impact of the RT-PCR test false-negative results for SARS-CoV-2 surveillance in Mexico}

Isaac Núñez, Pablo F. Belaunzarán, Yanink Caro-Vega. Rev Invest Clin 2021;73:120-126.

Underestimation of the number of cases during the COVID-19 pandemic is a constant concern worldwide, particularly because of the suboptimal sensitivity of detection of viral RNA using RT-PCR, which is the most common technique to confirm a case. In this study, Núñez et al. ${ }^{22}$ applied mathematical modeling strategies to provide corrected estimates of the number of cases, hospitalizations in Intensive Care Units (ICU), and deaths among people tested for SARS-CoV-2 in Mexico in a period of 6 months, considering the probability of RT-PCR false negative test results. They found that the number of cases reported in the publicly available national databases during that period was underestimated by $28 \%$, the number of patients at the ICU by $15 \%$, and the number of deaths by $8 \%$. Considering that only a small proportion of symptomatic cases seeking healthcare are tested, the true underestimation of COVID-19 cases may be much higher. This study represents a call of attention to the official health authorities in Mexico to take into account these underestimating figures when establishing health policies on the SARS-CoV-2 pandemic, and to consider expanding the testing capacity in order to make safe progressive reopening. This is important to prevent a new outbreak of the disease and further confinement, which may be disastrous for the economy of the country. 


\section{Methylene blue (MB) for treatment of hospitalized COVID-19 patients: a randomized, controlled, open-label clinical trial, and phase 2}

Daryoush Hamidi-Alamdari, Saied Hafizi-Lotfabadi, Ahmad Bagheri-Moghaddam, Hossin Safari, Mahnaz Mozdourian, Zahra Javidarabshahi Z., et al. Rev Invest Clin 2021;73:190-198.

COVID-19 has spread rapidly worldwide, and it is urgent to explore effective treatments to protect patients from developing severe illness. In this context, it was recently reported that methylene blue (MB) inhibited the entry of a SARS-CoV-2 spike bearing pseudovirus into ACE2-expressing cells, suggesting a possible therapeutic option ${ }^{23}$. Thus, in this multi-author study, the effect of MB was explored in 80 hospitalized patients with severe COVID-19 that were randomly selected to receive either oral $\mathrm{MB}$ along with standard of care (SOC) or SOC only ${ }^{24}$. MB syrup was administered orally during 2 weeks. The results showed that the addition of MB to the treatment protocol significantly improved oxygen saturation and clinical respiratory distress, without serious adverse events, decreasing hospital stay, and mortality. This finding suggests that MB may be useful as a complementary therapy in patients with COVID-19 and severe respiratory disease, although studies with larger cohorts still are necessary.

\section{SELECTED REVIEWS}

\section{Aging and pulmonary fibrosis}

Moisés Selman, Ivette Buendía-Roldán, Annie Pardo. Rev Invest Clin. 2016;68:75-83.

Idiopathic pulmonary fibrosis (IPF) is a progressive disease of unknown etiology, and by far the most aggressive of the fibrotic lung disorders. Aging is a driving force of the disease, although the mechanisms linking age with IPF are unclear. In this review included in the thematic issue Aging and Disease, Selman et al. ${ }^{25}$ explore the contribution of the main hallmarks of aging in the development of IPF, dissecting the putative role of genomic instability, cellular senescence, mitochondrial dysfunction, telomere shortening, loss of proteostasis, stem-cell exhaustion, deregulated nutrient sensing, and epigenetic alterations, including modifications in DNA methylation and noncoding RNA. The authors demonstrated that most of these aging-associated characteristics are occurring prematurely or excessively in the IPF lungs affecting primarily the lung epithelium, additionally confirming that this is an epithelial-driven disease ${ }^{26}$.

\section{Genetic risk assessment for breast cancer (BC) in Latin America (LA)}

Yanin Chavarri-Guerra Y, Kathleen Reilly Blazer K, Jeffrey Nelson Weitzel. Rev Invest Clin 2017;69:94-102.

Breast cancer $(B C)$ is the most prevalent malignancy in women from Latin America (LA), and it is becoming even more frequent among young women living in this region. In this article, included in the thematic issue $B C$ in Young Women, Chavarri-Guerra et al., ${ }^{27}$ a group of experts in BC, review an important aspect of this neoplasia, the genetic issue problem in LA, emphasizing on the marked barriers for access to genetic care, particularly in limited-resource settings. They nicely review the BRCA mutations (which are responsible for around $40 \%$ of hereditary breast and ovarian cancer cases) and other BC-associated genes detected in LA, and also summarize the access to genetic cancer risk assessment, availability of genetic testing, and genetic cancer risk assessment programs in LA at the time of publication of this review. The authors conclude that there is an urgent need for the development and implementation of genetic cancer risk assessment programs in LA as well as for improving the education of health-care personnel and allocation of existing resources to provide genetic testing at reasonable costs. Although some progress in this important issue has been achieved, those needs are still not being met ${ }^{28}$. Preventing and decreasing the burden of $B C$ in the region, mostly represented by underdeveloped countries, should be a health priority.

Non-nutritive sweeteners (NNS): Evidence on their association with metabolic diseases and potential effects on glucose metabolism and appetite

Alfonso Romo-Romo, Carlos A. Aguilar-Salinas, Rita A. Gómez-Díaz, Griselda X. Brito-Córdova, Donají V. Gómez-Velasco, María J. López-Rocha, Paloma Almeda-Valdez. Rev Invest Clin 2017;69:129-138. 
NNS have frequently been used all over the world for decades and, in fact, many health-care providers generally recommend their use to replace regular sugar consumption to get a sweet taste in patients without obesity or diabetes mellitus or any other metabolic disease, in whom the indication for its therapeutic use may be medically justified ${ }^{29}$. In this review by RomoRomo et al. ${ }^{30}$, the authors analyzed and discuss several aspects related to this important issue, including the evidence on the metabolic effects of sweeteners, their safety aspects as well as the scientific evidence from observational and clinical trials in humans that question that these types of sweeteners are innocuous for general health. The literature review on this particular topic is quite complete and critically analyzed by the authors, and concludes that NNS should be advised only in the specific conditions mentioned above; in fact, both the American Diabetes Association and the American Heart Association ${ }^{29}$ suggest that the NNS can be useful when complemented with a well-structured diet. Nevertheless, the authors also conclude that convincing evidence of the effects on the metabolic and appetite hormones of NSS is not available yet, emphasizing on the need of adequately designed, well-controlled studies to solve definitively the controversial issues on the negative effects on health provoked by longstanding NNS use. If so, then should some NNS be considered as endocrine disruptors as suggested by in vitro studies ${ }^{31}$ ?

\section{Integrative view of the mechanisms that induce acute kidney injury (AKI) and its transition to chronic kidney disease (CKD)}

Luis Enrique García-Ortuño, Norma A. Bobadilla. Rev Invest Clin 2018;70:261-268.

In this interesting review, García-Ortuño and Bobadil$\mathrm{la}^{32}$ nicely discuss the mechanisms subserving the transition from AKI to CKD, a relatively frequent condition that in any stage affects $7-12 \%$ of the population in diverse regions of the world (e.g., in Mexico) and that lead to systemic complications including accelerated cardiovascular disease and death ${ }^{33}$. The authors briefly address different recently published evidence unveiling the physiopathogenic mechanisms involved in the transition from AKI to CKD. These mechanisms include endothelial and proximal tubular epithelium injury and the concurrent activation of inflammatory processes triggering different signaling pathways that eventually lead to tubulointerstitial fibrosis, chronic hypoxia, and deterioration of functional tissue. They also discuss the role of sexual dimorphism in this transition, briefly describing experimental data from their own laboratory suggesting that a male hormonal milieu favors the development of CKD after AKI. Early identification of AKI, particularly in hospitalized patients, is important to prevent progression to CKD and reduce the high costs of the long-term effects of this condition.

\section{Respiratory impact of electronic cigarettes and low-risk tobacco}

Ireri Thirión-Romero I., Rogelio Pérez-Padilla, Gustavo Zabert, Inti Barrientos-Gutiérrez. Rev Invest Clin 2019; 71:17-27.

Electronic cigarettes or e-cigarettes, also known as electronic nicotine dispensing systems (ENDS), appeared in the market more than a decade ago and gained popularity because they were considered a less harmful alternative to conventional cigarette smoking ${ }^{34}$. In this review, included in the thematic issue Chronic Obstructive Pulmonary Disease, the authors demystify this concept giving evidence that exposure to e-cigarettes provokes a variety of abnormalities in vitro, in animal models, and in humans, including airway inflammation, decrease in the immune response, and increase of oxidative stress and endothelial/vascular dysfunction, among others ${ }^{35}$. Moreover, they cast doubt about the role of e-cigarettes as an option for reducing cigarette consumption or for smoking cessation as it was proposed. Actually, e-cigarette initiation in a never-smoke youth may not only cause harm but also may stimulate to smoke regular cigarettes.

\section{CONCLUSIONS}

We have presented here the summaries from original and review articles published in the RIC -Clinical and Translational Investigation- in the last 6 years that were carefully selected by the Editors on the basis of their translational implications. It is expected that as the IF of the journal increases, more studies containing novel information with a translational character will be considered for publication, making the journal more competitive and attractive not only for national 
but also for international authors. Meanwhile, we should continue selecting for peer review and publication the best articles based on the expert opinion of the editors and reviewers, considering originality, study design, application of new technologies, validation, and meaningful scientific conclusions. In addition to selecting for publication those manuscripts that meet these characteristics, the new version of the RIC will also continue promoting the publication of results from interdisciplinary research on emerging and important clinical problems of interest to both the national and international community of physicians, scientists, and health providers. This is the challenge that we, the Editors and the Editorial Committee of the current version of the RIC must accomplish with passion and devotion as the journal's founders did.

\section{ACKNOWLEDGMENTS}

The authors deeply thank the Associate Editors, the members of the Editorial Board, and the reviewers of the RIC - Clinical and Translational Investigation- for their invaluable work and collaboration to the success of the journal.

\section{REFERENCES}

1. Gamba G, Wolpert-Barraza E, Loria A, Ulloa-Aguirre A. The evolving history of the Revista de Investigación Clínica. Rev Invest Clin. 2021;73:270-9.

2. Serra-García M, Gneezy U. Non replicable publications are cited more than replicable ones. Sci Adv. 2021;7:eabd1705

3. Corona-Lau C, Muñoz L, Wolpert E, Aguilar LM, Dehesa M, Gutiérrez C, et al. Hepatitis C screening in the general population. Rev Invest Clin. 2015;67:104-8.

4. Soun JE, Chow DS, Nagamine M, Takhtawala RS, Filippi CG, Yu $W$, et al. Artificial Intelligence and acute stroke imaging. AJNR Am J Neuroradiol. 2021;42:2-11.

5. Zhang X, Li Y, Liang Y, Sun P, Wu X, Song J, et al. Distinguishing intracerebral hemorrhage from acute cerebral infarction through metabolomics. Rev Invest Clin. 2017;69:319-28.

6. Ellison S, Abdulrahim JW, Kwee LC, Bihlmeyer NA, Pagidipati N, McGarrah R, et al. Novel plasma biomarkers improve discrimination of metabolic health independent of weight. Sci Rep. 2020;10:21365

7. Bhardwaj R, Parker MC. Palliative therapy of colorectal carcinoma: stent or surgery? Colorectal Dis 2003;5:518-21.

8. Yang $P$, Lin XF, Lin K, Li W. The role of stents as bridge to surgery for acute left-sided obstructive colorectal cancer: meta-analysis of randomized controlled trials. Rev Invest Clin. 2018;70:269-78.

9. Pacheco-Barcia V, Mondéjar R, Martínez-Sáez O, Longo F, Moreno JA, Rogado J, et al. Safety and oncological outcomes of bevacizumab therapy in patients with advanced colorectal cancer and self-expandable metal stents. Clin Colorectal Cancer. 2019;18:e287-93.

10. Bayat Z, Guttman MP, Shiroky J, Karanicolas PJ. Non-operative management of small bowel obstruction in patients with no previous abdominal surgery: a systematic review and metaanalysis. World J Surg. 2021;45:2092-9.

11. Acun G, Ozdemir H, Sunamak O, Ozdemir ZU, Baskan E, Yazi $M$, et al. The effect of single-dose intraperitoneal bevaci- zumab on peritoneal adhesion formation. Rev Invest Clin. 2018;70:279-84

12. Tang J, Xiang Z, Bernards MT, Chen S. Peritoneal adhesions: occurrence, prevention and experimental models. Acta Biomater. 2020;116:84-104

13. Pirillo A, Casula M, Olmastroni E, Norata GD, Catapano AL. Global epidemiology of dyslipidaemias. Nat Rev Cardiol. 2021 [Epub ahead of print].

14. Bello-Chavolla OY, Aguilar-Salinas CA. Factors influencing achievement of low-density lipoprotein cholesterol goals in Mexico: the international cholesterol management practice study. Rev Invest Clin. 2019;71:408-16.

15. Wiersinga WJ, Rhodes A, Cheng AC, Peacock SJ, Prescott HC. Pathophysiology, transmission, diagnosis, and treatment of coronavirus disease 2019 (COVID-19): a review. JAMA. 2020;324:782-93.

16. Bose-O'Reilly S, Daanen H, Deering K, Gerrett N, Huynen MM Lee J, et al. COVID-19 and heat waves: new challenges for healthcare systems. Environ Res. 2021;198:111153

17. Ortiz-Brizuela E, Villanueva-Reza M, González-Lara MF, TamezTorres KM, Román-Montes CM, Díaz-Mejía BA, et al. Clinical and epidemiological characteristics of patients diagnosed with COVID-19 in a tertiary care center in Mexico city: a prospective cohort study. Rev Invest Clin. 2020;72:252-8.

18. Shaya GE, Leucker TM, Jones SR, Martin SS, Toth PP. Coronary heart disease risk: low-density lipoprotein and beyond. Trends Cardiovasc Med. 2021 [Epub ahead of print]

19. Cardoso-Saldaña GC, Posadas-Sánchez R, González-Salazar MC, Fragoso-Lona LM, Vargas-Alarcón G. Coronary artery calcium is associated with Ipa gene variant rs7765803-c in Mexican Mestizo population. The Gea project. Rev Invest Clin. 2020;72:61-8.

20. Barrios Hernández AE, Durand-Carbajal M, Vega CC, Larrea $F$. Analysis of the endometrial transcriptome at the time of implantation in women receiving a single post-ovulatory dose of levonorgestrel or mifepristone. Rev Invest Clin. 2020;72:363-71.

21. Durand $M$, del Carmen CM, Raymond EG, Durán-Sánchez O, De la Luz Cruz-Hinojosa M, Castell-Rodríguez A, et al. On the mechanism of action of short-term levonorgestrel administration in emergency contraception. Contraception. 2001;64:227-34.

22. Núñez I, Belaunzarán PF Caro-Vega F. Impact of the RT-PCR test false-negative results for SARS-CoV-2 surveillance in Mexico. Rev Invest Clin. 2021;73:120-6.

23. Bojadzic D, Alcazar O, Buchwald P. Methylene blue inhibits the SARS-CoV-2 spike-ACE2 protein-protein interaction-a mechanism that can contribute to its antiviral activity against COVID-19. Front Pharmacol. 2021;11:600372.

24. Hamidi-Alamdari D, Hafizi-Lotfabadi S, Bagheri-Moghaddam A, Safari HJ, Mozdourian M, Javidarabshahi Z, et al. Methylene blue for treatment of hospitalized COVID-19 patients: a randomized, controlled, open-label clinical trial, phase 2. Rev Invest Clin. 2021;73:190-8.

25. Selman M, Buendía-Roldán I, Pardo A. Aging and pulmonary fibrosis. Rev Invest Clin. 2016;68:75-83.

26. King TE Jr., Pardo A, Selman M. Idiopathic pulmonary fibrosis. Lancet. 2011;378:1949-61.

27. Chavarri-Guerra Y, Reilly Blazer K Nelson Weitzel ]. Genetic risk assessment for breast cancer in Latin America. Rev Invest Clin. 2017;69:94-102

28. Alvárez-Gómez RM, De la Fuente Hernández MA, Montalvo LH, Hidalgo-Miranda A. Challenges of diagnostic genomics in Latin America. Curr Opin Genet Dev. 2021;66:101-9.

29. Gardner CH, Wylie-Rosett J, Gidding SS, Steffen LM, Johnson RK, Reader D, et al. Nutritive sweeteners: current use and health perspectives. Circulation. 2012;126:509-19.

30. Romo-Romo A, Aguilar-Salinas C, Gómez-Díaz R, Brito-Córdova GX, Gómez-Velasco DV, López-Rocha MJ, et al. Non-nutritive sweeteners: evidence on their association with metabolic diseases and potential effects on glucose metabolism and appetite. Rev Invest Clin. 2017;69:129-38

31. Shannon M, Rehfeld A, Frizzell C, Livingstone $\mathrm{CH}, \mathrm{McGonagle} \mathrm{C,}$ Skakkebaek NE, et al. In vitro bioassay investigations of the endocrine disrupting potential of steviol glycosides and their metabolite steviol, components of the natural sweetener Stevia. Mol Cell Endocrinol. 2016;427:65-72.

32. García-Ortuño LE, Bobadilla NA. Integrative view of the mechanisms that induce acute kidney injury and its transition to chronic kidney disease. Rev Invest Clin. 2018;70:261-8.

33. Romagnani P, Remussi G, Glassock R, Levin A, Jager KJ, Tonelli $M$, et al. Chronic kidney disease. Nature Rev. 2017:3:17088.

34. Marques P, Piqueras L, Sanz MJ. An updated overview of e-cigarette impact on human health. Respir Res. 2021;22:151.

35. Thirión-Romero I, Pérez-Padilla R, Zabert G, Barrientos-Gutierrez I. Respiratory impact of electronic cigarettes and low-risk tabacco. Rev Invest Clin. 2019;71:17-27. 